\title{
THEORETICAL EVALUATION OF THE EFFECT OF SURFACES PROCESSED WITH ABRASIVE WATER JET ON FATIGUE LIFE
}

\begin{abstract}
Summary
Surface roughness is an effective factor in determining the fatigue life of machine elements. Roughness of the surface results in the notch effect, and if the notch effect increases, the fatigue life of the material is shortened. $20 \mathrm{~mm}$ thick steel AISI 1050 (CK45, DIN 1.0540, EN C50) was cut into $80 \times 80 \mathrm{~mm}$ squares by applying the abrasive water jet machining technique. The square cutting operations were carried out at five different feed rates $(10,16,24,34$ and $45 \mathrm{~mm} / \mathrm{min})$ and the other cutting parameters were kept constant. The $R z$ and $S m$ surface roughness values of the four surfaces obtained at each feed rate were measured. The effect of the feed rates on the surface roughness was investigated. Also, by applying the Murakami surface roughness fatigue model, the effects on the theoretical fatigue life of the surface roughness resulting from the chosen feed rates were modelled. Furthermore, the reason for the difference in surface roughness values between the first, the second, the third and the fourth surface at each feed rate was investigated. As a result, an increase in the feed rate causes an increase in surface roughness values, which in turn shortens the fatigue life of the material. The surface roughness value measured on the first surface of the four cutting surfaces obtained at the same feed rate increases on each surface and reaches the highest value on the fourth surface.
\end{abstract}

Key words: $\quad$ abrasive water jet, AISI 1050 tool steel, surface roughness, fatigue

\section{Introduction}

Different manufacturing techniques provide different surface quality which exerts considerable influence on the fatigue life of machine elements. It has been known for a long time that fatigue damage usually starts from cracked surfaces and surface roughness starts in peak-valley zones. Abrasive water jet (AWJ) technology is a machining process in which the material is cut by high-pressure water and a mixture of abrasive hard powder of micron size [1-4]. The creation of erosion on the part due to the impact of high pressure water and abrasive particles breaks the bonds between the atoms, causing the workpiece to wear out in a narrow range [5-6]. The AWJ technique does not generate heat in the processing zone during the process of erosion of the workpiece material. Therefore, the absence of heat in the processing zone has a great importance in terms of machining performance and surface integrity [1,7-10]. There are few studies on water jet and fatigue strength. Stenberg et al. [11] 
investigated the high frequency tensile fatigue behaviour of surface quality generated in standard size specimens cut by oxygen, plasma, laser and water jet, and they found that the surface roughness parameters $R a$ and $R z$ were the lowest and the average residual stresses were the highest on the surface of the cut samples. They also found that the fatigue life values were higher in the water jet cutting technique after plasma cutting with oxygen compared to other cutting methods. Some of the studies deal with the process of turning using AWJ, usually with the effect of abrasive type and size on machinability and surface structure. In a study by John L. Ohman [12], the abrasive hardness increases the feed rate and depth of processing with AWJ and at a high feed rate of coarse-grained abrasives (50 mesh), the surface roughness of small-size abrasives (120 mesh) yielded lower cuts. In an experimental study [13], $\mathrm{Al}_{2} \mathrm{O}_{3}$ and garnet powders as abrasive types were tested by cutting the glass/epoxy layer composite material by water jet, and it has been found that harder $\mathrm{Al}_{2} \mathrm{O}_{3}$ powdered sections have smoother surfaces and are less conical. In a study in which aluminum plates were cut at different feed rates [14], abrasive grades of $320 \mathrm{~g} / \mathrm{min}$ for $15 \mathrm{~mm}$ thick plates and of $390 \mathrm{~g} / \mathrm{min}$ for $30 \mathrm{~mm}$ thick plates were used. It has been emphasized that increasing the depth of the cut and the feed rate advance, the surface roughness increases significantly especially towards the outlet of the water. In his water jet study Akkurt [15] processed steel workpieces of 5-10-15-20 mm in thickness that have thicknesses different from the AISI 1030 steel and found that $5 \mathrm{~mm}$ thick samples have low surface roughness and the surface roughness increases with an increase in the cutting depth due to an increase in the material thickness. Limbachiya and Patel found in their study [16] that the rate of workpiece processing increases from $44.08 \mathrm{~mm}^{3} / \min$ to $55.43 \mathrm{~mm}^{3} /$ min with an increase in the abrasive flow rate and the feed rate. In their study on cutting with ASJ, Chao and Geskin [17] concluded that the nozzle vibration reduces the roughness values by changing the appearance of the linear roughness structure. Reddy et al. [18] were cutting $6 \mathrm{~mm}$ thick Inconel sheets using 80 mesh garnet powders as abrasive in AWJ with different processing values. They pointed out that an increase in the amount of nozzle advancement and the nozzle-workpiece distance increases the surface roughness, and an increase in the abrasive ratio reduces the surface roughness increasing the processing speed [18].

As a result of the literature review, it has been understood that the effect of the surface quality achieved by the AWJ process on the fatigue life of the material after manufacturing has been rarely investigated. Generally, the fatigue strength of the materials used to produce machine elements is determined according to the pre-manufacturing standard tests. And these values are used by designers in their engineering calculations to determine the fatigue life of machine parts. However, it is obvious that after water jet machining, just like after every manufacturing process surface roughness inevitably occurs and roughness structures are different. So, it is well known that the type of the surface roughness structure consists of a linear-parabolic combination, and the roughness of the peak-valley dots will accumulate stress in machine elements. As a result, the roughness structure and value after manufacturing decreases the fatigue life determined for produced raw metals. Therefore, the surface roughness that occurs after the completion of the manufacturing process is a phenomenon that results in a decrease in the fatigue strength of machine elements and has a triggering effect of causing plastic deformation. So, the calculation of the theoretical fatigue life is very useful after manufacturing parts. For this purpose, the surface roughness of the AISI 1050 steel was processed with water jetting at various feed rates to theoretically predict how the fatigue life will change after manufacturing. In these calculations, the $\sqrt{\text { area }}$ model by Murakami was used. In his fatigue studies that included also experiments, Murakami found that the geometry of surface imperfections was useful as a model parameter in the " $\sqrt{\text { area }}$ " model he developed. The results obtained from the experimental studies are in agreement with numerical calculations [19]. In the developed and accepted model, the wavy structure of surface roughness is defined as a shallow gap or a deep notch and this area of the top and the pit is called $\sqrt{\text { area }}$. 


\section{Theoretical and experimental method}
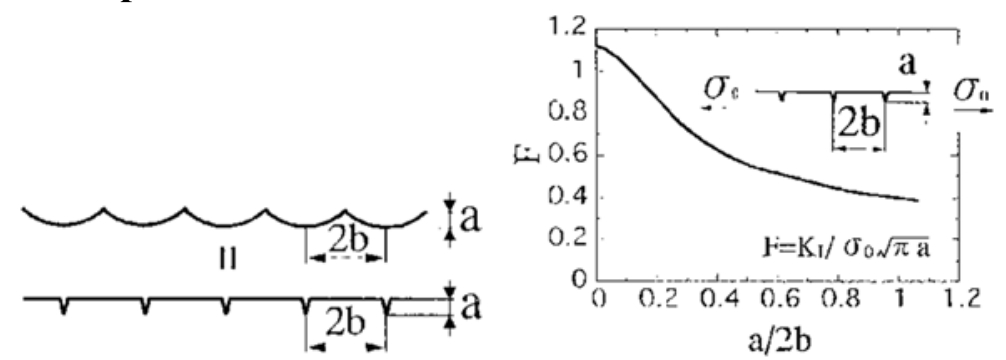

Fig. 1 Change in tensile strength of periodic surface roughness notches [19].

Figure 1 shows the tensile strength factor Kt for periodic roughness intervals on the proccessed surface. The term " $\mathrm{F}$ " is a geometric correction factor that depends on the depth and spacing of the cracks on the surface and $\mathrm{K}_{\mathrm{t}}$ is defined as a function of $\mathrm{HV}$ by the following equation:

$$
\mathrm{K}_{\mathrm{t}}=\Delta \mathrm{K}_{\mathrm{th}}=(3.3) \cdot 10^{-3}(\mathrm{HV}+120) \cdot(\sqrt{\text { area }})^{1 / 3}
$$

In modelling the surface roughness of the insulator with respect to fatigue, Figure 1 describes the width and the depth of the roughness wave with expressions $2 b$ and $2 a$, respectively. In this study, parameters $R z$ and $S m$, which express these definitions in standard roughness measurements, are used in the theoretical calculations. The average of the maximum peak and depression values $(R t)$ measured in the $R z$ measurement range is schematically shown in Figure 2.

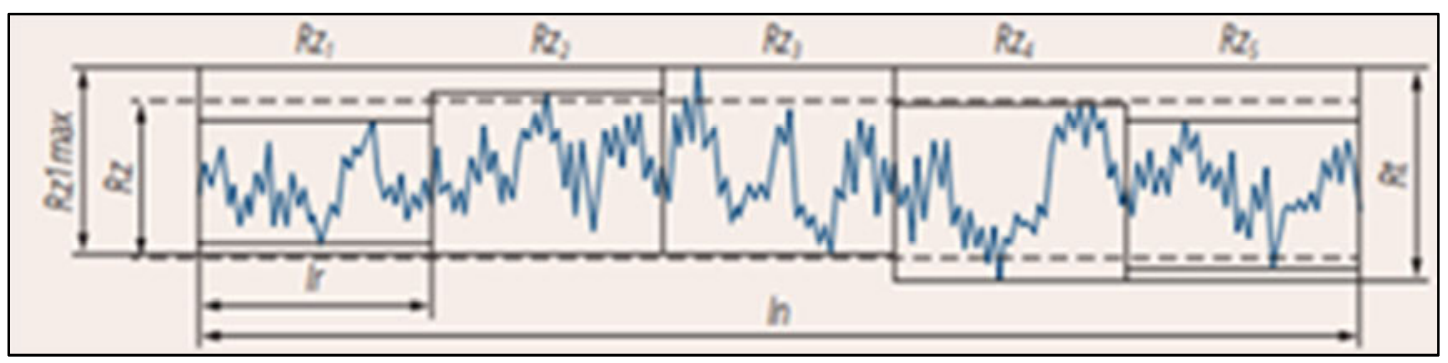

Fig. 2 Roughness at maximum peak height according to the reference line in the measurement range (EN ISO 4287)

$$
R z=\frac{R_{t 1}+R_{t 2} \ldots \ldots \ldots \ldots \ldots+R_{t n}}{n}=\frac{1}{n} \sum_{i=1}^{n} R_{t i}
$$

"Sm" is defined as the distance between the roughness peak points in the measurement length (Figure 3.) and it represents the term " $2 b$ " as well as $R z$ values used instead of " $a$ " term in the fatigue model for calculating $\sqrt{\text { area }}$. In the fatigue calculations and roughness measurements, these two standardized exact measurement values are used in the theoretical model, Eq. 2.5.

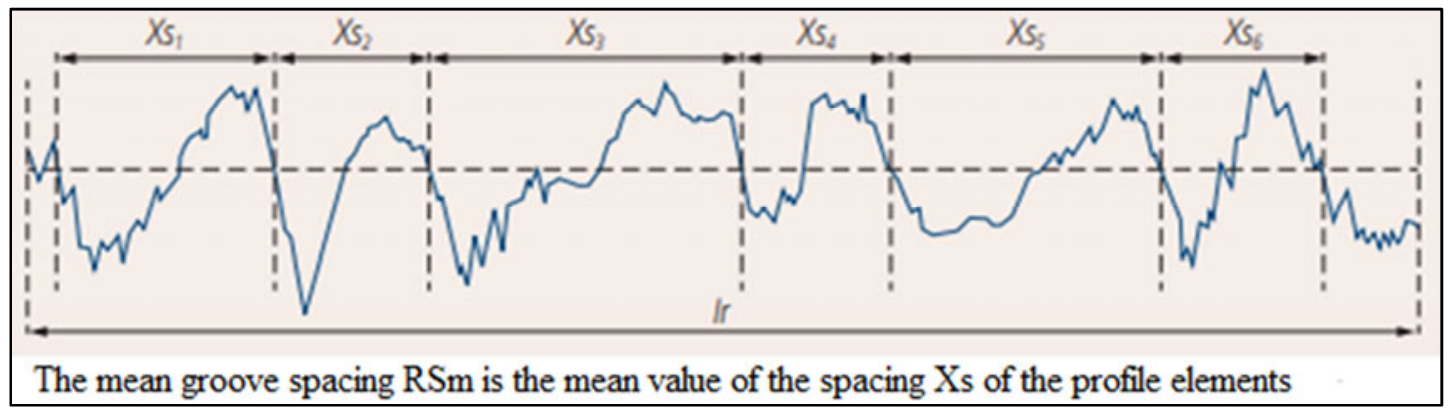

Fig. 3 Roughness distance between peak points (EN ISO 4287) 
In the estimation model proposed by Murakami, $\mathrm{R}=-1$ is defined as stress rate. That is, the fully variable dynamic fatigue state is considered. Here, $\sqrt{\text { area }}$ is the error dimension that expresses profile waves on the surface. Equations 2.3 and 2.4 are equations for calculating $\sqrt{\text { area }}$ for the range of the roughness values given in the general fatigue life formula:

$$
\begin{array}{ll}
(\text { area })^{1 / 2} \mathrm{R} / 2 b \cong 2.97(a / 2 b)-3.51(a / 2 b)^{2}-9.74(a / 2 b)^{3} & a / 2 b<0.195 \\
(\text { area })^{1 / 2} \mathrm{R} / 2 b \cong 0.38 & a / 2 b>0.195 \\
\sigma_{\mathrm{w}}=\frac{1.43(\mathrm{HV}+120)}{(\sqrt{\text { area }})^{1 / 6}}\left[\frac{1-\mathrm{R}}{2}\right]^{\alpha} &
\end{array}
$$

In Equation 2.5, the fatigue life of surface roughness gaps and pits can be estimated by subsituting the values, and HV is here the constant measured hardness of the AISI 1050 metal and the $\sqrt{\text { area }}$ values are calculated by Equations 2.3 and 2.5. So, " $\sigma_{\mathrm{w}}$ " is the allowable theoretical fatigue life and " $\alpha$ " is the stress sensitivity factor and is expressed as:

$$
\alpha=0.226+\mathrm{HV} \cdot 10^{-4} \text {. }
$$

The stress ratio "R" is defined by the following general formula, and $\sigma_{m}$ is the average stress in the following equation:

$$
\mathrm{R}=\frac{\sigma_{\min }}{\sigma_{\max }}
$$

Another parameter that Murakami has developed with the $\sqrt{\text { area }}$ model is the stress intensity factor which expresses the accumulation of stresses in the surface roughness discontinuities. If this factor is known, the size of all stresses and strains in the notch region can be determined. When these stress values reach a certain threshold value, a crack progresses.

In this study, a KMT SL VI STREAMLINE pressure pump producing 4000 bar pressure was used. A USEL INTERJET CNC WJ 2040 abrasive water jet (AWJ) bench with a $2000 \times 4000 \mathrm{~mm}$ working surface was used (Figure 4). In the experiments, the $20 \mathrm{~mm}$ thick AISI 1050 tool steel material, which is difficult to be formed by conventional methods, is cut into $80 \times 80 \mathrm{~mm}$ squares. Five different feed rates were obtained based on the cutting values of the AWJ machine's automatic abrasive transfer system and the cut-off values recommended by the FAGOR software, which is used in the CNC control unit. In the study, apart from the feed rate change, all other processing parameters are fixed for each experiment: the material is cut in squares of $80 \times 80 \mathrm{~mm}$ in dimension and the processing parameters used in the experiments are given in Table 1. In the experimental work, garnet powder was used in the 80 mesh average grain size, which is widely used in the industry and a fresh powder filler was used each time in the abrasive powder chamber for each different nozzle feed rate. The reason for the new powder filling at each feed rate is that the powder size is not the same in every pile.

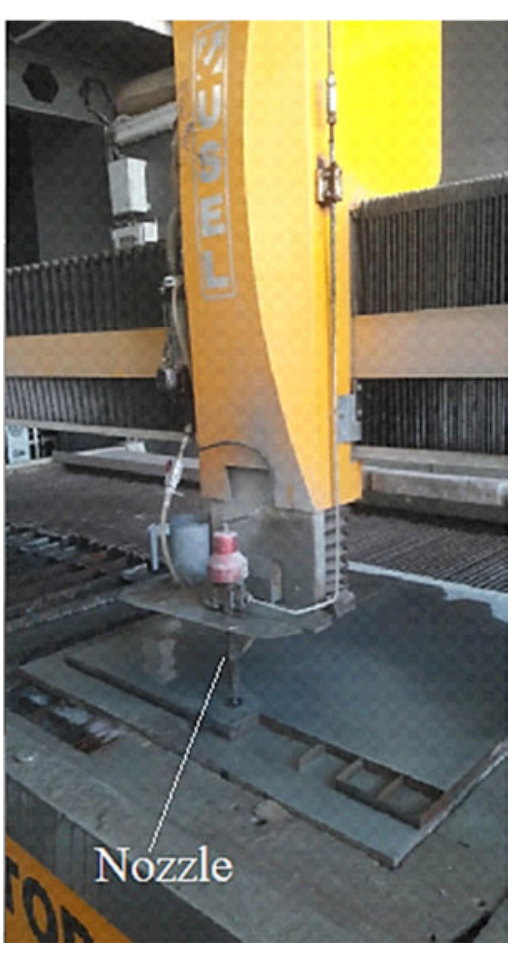

Fig. 4 AWJ machine USEL INTERJET CNC WJ 2040 used for processing 
Table 1 Processing parameters

\begin{tabular}{ccccccccc}
\hline $\begin{array}{c}\text { Material } \\
\text { AISI 1050 }\end{array}$ & $\begin{array}{c}\text { Feed rate } \\
(\mathbf{m m} / \mathbf{m i n})\end{array}$ & $\begin{array}{c}\text { Cutting time } \\
(\mathbf{m i m} \mathbf{s e c} . \mathbf{s})\end{array}$ & $\begin{array}{c}\text { Water } \\
\text { pressure } \\
(\mathbf{b a r})\end{array}$ & $\begin{array}{c}\text { Sand } \\
\text { rate } \\
\mathbf{( \% )}\end{array}$ & $\begin{array}{c}\text { Sand } \\
\text { thickness } \\
(\mathbf{m e s h})\end{array}$ & $\begin{array}{c}\text { Cutting } \\
\text { height } \\
(\mathbf{m m})\end{array}$ & $\begin{array}{c}\text { Nozzle } \\
\text { diameter } \\
(\mathbf{m m})\end{array}$ & $\begin{array}{c}\text { Orifice } \\
\text { diameter } \\
(\mathbf{m m})\end{array}$ \\
\hline $1^{\text {st }}$ test & 10 & $32: 31: 60$ & 3800 & 50 & 80 & 2 & 1.02 & 0.27 \\
\hline $2^{\text {nd }}$ test & 16 & $20: 24: 52$ & 3800 & 50 & 80 & 2 & 1.02 & 0.27 \\
\hline $3^{\text {rd }}$ test & 24 & $13: 34: 53$ & 3800 & 50 & 80 & 2 & 1.02 & 0.27 \\
\hline $4^{\text {th }}$ test & 34 & $9: 41: 65$ & 3800 & 50 & 80 & 2 & 1.02 & 0.27 \\
\hline $5^{\text {th }}$ test & 45 & $7: 11: 09$ & 3800 & 50 & 80 & 2 & 1.02 & 0.27 \\
\hline
\end{tabular}

After cutting at different feed rates, the surface roughness values $R t, R z$ and $S m$ were measured after the chip removal by applying erosion on the AISI 1050 steel workpiece, and the effects on the processing speed and the theoretical fatigue life were investigated. Surface roughness was measured as shown in Figure 5 and the measurements were made using a Mitutoyo Surftest SJ-210 measuring instrument. The surface roughness was measured at $3 \mathrm{~mm}, 6 \mathrm{~mm}, 10 \mathrm{~mm}, 14 \mathrm{~mm}$ and $17 \mathrm{~mm}$ distances from the upper surface of each part. The arithmetic mean of the three values measured on each measurement line was taken and the $R a, R z$ and $S m$ values were obtained. The surface roughness measurement values are given in Table 2.

Table 2 Surface roughness measurement values

\begin{tabular}{|c|c|c|c|c|c|c|}
\hline FEED RATE & $\begin{array}{c}\text { SURFACE } \\
\text { ROUGHNESS }\end{array}$ & $\begin{array}{c}\text { 1st } \\
\text { SURFACE }\end{array}$ & $\begin{array}{c}\text { 2nd } \\
\text { SURFACE }\end{array}$ & $\begin{array}{c}\text { 3rd } \\
\text { SURFACE }\end{array}$ & $\begin{array}{c}\text { 4th } \\
\text { SURFACE }\end{array}$ & $\begin{array}{l}\text { MEASUREMENT } \\
\text { LINE }\end{array}$ \\
\hline \multirow{16}{*}{$10 \mathrm{~mm} / \mathrm{min}$} & \multirow{2}{*}{\multicolumn{5}{|c|}{ 1st WORKPIECE }} & \\
\hline & $R a$ & 1.509 & & & & \multirow{3}{*}{1} \\
\hline & $R z$ & 9.839 & 12.248 & 12.888 & 12.188 & \\
\hline & $\mathrm{Sm}$ & 131.667 & 181.767 & 119.2 & 150 & \\
\hline & $R a$ & 1.636 & 2.082 & 2.224 & 2.288 & \multirow{3}{*}{2} \\
\hline & $R z$ & 10.384 & 14.447 & 15.839 & 14.126 & \\
\hline & $S m$ & 119.034 & 145.634 & 150.8 & 136.234 & \\
\hline & $R a$ & 1.834 & 2.199 & 2.305 & 2.453 & \multirow{3}{*}{3} \\
\hline & $R z$ & 10.671 & 14.512 & 14.162 & 21.394 & \\
\hline & $S m$ & 161.034 & 118 & 149.6 & 190.7 & \\
\hline & $R a$ & 1.989 & 2.379 & 2.445 & 2.668 & \multirow{3}{*}{4} \\
\hline & $R z$ & 11.679 & 16.502 & 16.034 & 14.945 & \\
\hline & $S m$ & 163.034 & 198.434 & 185.167 & 133.867 & \\
\hline & $R a$ & 2.207 & 2.604 & 2.826 & 3.147 & \multirow{3}{*}{5} \\
\hline & $R z$ & 12.762 & 17.032 & 14.108 & 17.538 & \\
\hline & $\mathrm{Sm}$ & 201.1 & 286.7 & 355.3 & 212.467 & \\
\hline \multicolumn{7}{|c|}{ 2nd WORKPIECE } \\
\hline \multirow{15}{*}{$16 \mathrm{~mm} / \mathrm{min}$} & $R a$ & 1.845 & 2.034 & 2.052 & 2.140 & \multirow{3}{*}{1} \\
\hline & $R z$ & 12.965 & 12.874 & 12.188 & 14.071 & \\
\hline & $S m$ & 165.034 & 179.167 & 214.567 & 128.233 & \\
\hline & $R a$ & 2.121 & 2.106 & 2.128 & 2.217 & \multirow{3}{*}{2} \\
\hline & $R z$ & 15.576 & 13.386 & 13.436 & 12.324 & \\
\hline & $S m$ & 208.900 & 165.000 & 154.600 & 170.800 & \\
\hline & $R a$ & 2.218 & 2.200 & 2.284 & 2.315 & \multirow{3}{*}{3} \\
\hline & $R z$ & 14.355 & 13.441 & 14.067 & 14.825 & \\
\hline & $\mathrm{Sm}$ & 142.633 & 184.600 & 737.800 & 174.533 & \\
\hline & $R a$ & 2.393 & 2.369 & 2.566 & 2.380 & \multirow{3}{*}{4} \\
\hline & $R z$ & 14.373 & 14.577 & 15.409 & 13.689 & \\
\hline & $\mathrm{Sm}$ & 167.267 & 171.767 & 200.500 & 172.100 & \\
\hline & $R a$ & 2.855 & 2.752 & 3.483 & 2.658 & \multirow{3}{*}{5} \\
\hline & $R z$ & 16.512 & 15.992 & 18.552 & 16.607 & \\
\hline & $\mathrm{Sm}$ & 226.200 & 251.433 & 216.933 & 226.900 & \\
\hline
\end{tabular}


Table 2 (continued)

\begin{tabular}{|c|c|c|c|c|c|c|}
\hline FEED RATE & $\begin{array}{c}\text { SURFACE } \\
\text { ROUGHNESS }\end{array}$ & $\begin{array}{c}\text { 1st } \\
\text { SURFACE }\end{array}$ & $\begin{array}{c}\text { 2nd } \\
\text { SURFACE }\end{array}$ & $\begin{array}{c}\text { 3rd } \\
\text { SURFACE }\end{array}$ & $\begin{array}{c}\text { 4th } \\
\text { SURFACE }\end{array}$ & $\begin{array}{c}\text { MEASUREMEN } \\
\text { T LINE }\end{array}$ \\
\hline \multicolumn{7}{|c|}{ 3rd WORKPIECE } \\
\hline \multirow{15}{*}{$24 \mathrm{~mm} / \mathrm{min}$} & $R a$ & 2.064 & 2.062 & 2.045 & 2.199 & \multirow{3}{*}{1} \\
\hline & $R z$ & 12.289 & 11.630 & 12.928 & 12.174 & \\
\hline & $S m$ & 122.033 & 141.633 & 117.433 & 235.833 & \\
\hline & $R a$ & 2.237 & 2.243 & 2.178 & 2.387 & \multirow{3}{*}{2} \\
\hline & $R z$ & 15.412 & 14.120 & 12.761 & 17.188 & \\
\hline & $S m$ & 256.233 & 236.267 & 166.533 & 168.633 & \\
\hline & $R a$ & 2.430 & 2.405 & 2.343 & 2.867 & \multirow{3}{*}{3} \\
\hline & $R z$ & 14.527 & 13.469 & 13.203 & 16.056 & \\
\hline & $S m$ & 209.333 & 149.200 & 147.167 & 195.100 & \\
\hline & $R a$ & 2.569 & 2.832 & 2.796 & 2.762 & \multirow{3}{*}{4} \\
\hline & $R z$ & 14.104 & 19.305 & 16.110 & 17.182 & \\
\hline & $S m$ & 284.000 & 181.867 & 149.300 & 222.933 & \\
\hline & $R a$ & 3.029 & 2.780 & 3.192 & 3.277 & \multirow{3}{*}{5} \\
\hline & $R z$ & 15.484 & 14.855 & 18.416 & 16.128 & \\
\hline & $S m$ & 235.633 & 258.433 & 305.400 & 338.367 & \\
\hline \multicolumn{7}{|c|}{ 4th WORKPIECE } \\
\hline \multirow{15}{*}{$34 \mathrm{~mm} / \mathrm{min}$} & $R a$ & 2.150 & 2.172 & 2.068 & 2.241 & \multirow{3}{*}{1} \\
\hline & $R z$ & 13.532 & 15.464 & 12.414 & 14.174 & \\
\hline & $S m$ & 116.400 & 107.567 & 145.167 & 148.133 & \\
\hline & $R a$ & 2.488 & 2.332 & 2.259 & 2.521 & \multirow{3}{*}{2} \\
\hline & $R z$ & 15.268 & 14.469 & 14.033 & 14.646 & \\
\hline & $\mathrm{Sm}$ & 177.233 & 151.000 & 154.367 & 278.200 & \\
\hline & $R a$ & 2.629 & 2.462 & 2.504 & 2.622 & \multirow{3}{*}{3} \\
\hline & $R z$ & 17.943 & 14.990 & 14.587 & 17.747 & \\
\hline & $S m$ & 265.000 & 199.700 & 310.200 & 263.600 & \\
\hline & $R a$ & 2.811 & 2.986 & 2.610 & 2.836 & \multirow{3}{*}{4} \\
\hline & $R z$ & 15.847 & 17.846 & 15.623 & 16.962 & \\
\hline & $S m$ & 225.267 & 214.467 & 248.500 & 159.667 & \\
\hline & $R a$ & 3.390 & 3.781 & 3.074 & 3.823 & \multirow{3}{*}{5} \\
\hline & $R z$ & 21.818 & 20.234 & 17.779 & 19.960 & \\
\hline & $S m$ & 274.667 & 177.000 & 260.167 & 445.767 & \\
\hline \multicolumn{7}{|c|}{ 5th WORKPIECE } \\
\hline \multirow{15}{*}{$45 \mathrm{~mm} / \mathrm{min}$} & $R a$ & 2.152 & 2.283 & 2.403 & 2.502 & \multirow{3}{*}{1} \\
\hline & $R z$ & 13.369 & 13.686 & 16.490 & 17.440 & \\
\hline & $S m$ & 129.500 & 271.200 & 149.933 & 150.000 & \\
\hline & $R a$ & 2.901 & 2.531 & 2.693 & 2.781 & \multirow{3}{*}{2} \\
\hline & $R z$ & 15.169 & 15.404 & 15.431 & 15.786 & \\
\hline & $\mathrm{Sm}$ & 166.533 & 127.833 & 171.500 & 172.000 & \\
\hline & $R a$ & 2.953 & 2.836 & 2.794 & 2.831 & \multirow{3}{*}{3} \\
\hline & $R z$ & 18.536 & 16.944 & 14.857 & 15.345 & \\
\hline & $\mathrm{Sm}$ & 228.333 & 155.100 & 195.300 & 196.400 & \\
\hline & $R a$ & 3.295 & 3.335 & 3.167 & 3.266 & \multirow{3}{*}{4} \\
\hline & $R z$ & 20.035 & 19.586 & 17.521 & 18.655 & \\
\hline & $S m$ & 203.533 & 326.000 & 119.327 & 121.020 & \\
\hline & $R a$ & 4.132 & 5.363 & 3.737 & 4.011 & \multirow{3}{*}{5} \\
\hline & $R z$ & 19.718 & 26.756 & 20.318 & 21.833 & \\
\hline & $S m$ & 475.500 & 300.600 & 271.333 & 271.333 & \\
\hline
\end{tabular}




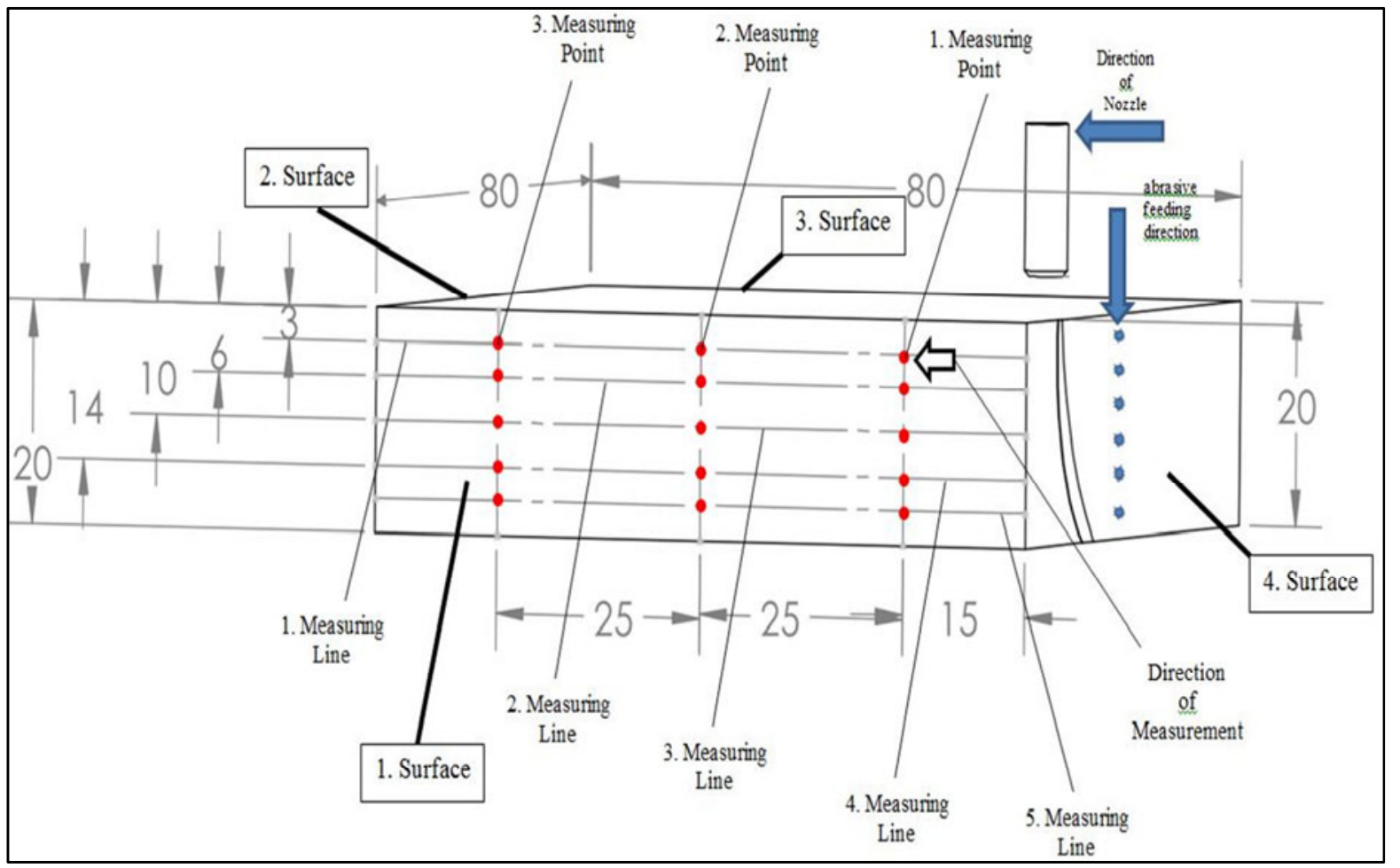

Fig. 5 Measurements of surface roughness on workpiece

\section{Discussion of experimental and theoretical findings}

The average surface roughness values $(R a)$ obtained from three different points on the test specimens processed by applying different parameters, the arithmetic means of five highest peaks and five deepest valleys along the sampling length profiles of these surfaces $(R z)$ and the largest peak distances $(\mathrm{Sm})$ on the profile are measured and averaged.

Another important criterion of the fatigue life in AWJ applications is surface quality or surface roughness. Surface roughness is evaluated under independent conditions. It is known that surface roughness can vary primarily depending on feed rate, water pressure, nozzle distance, abrasive powder type and size, and cutting depth. Higher surface roughness and surface roughness values were obtained with an increase in the feed rate. This effect reaches visibly noticeable levels towards the exit zone, i.e. the region where the deformation wear is observed, while the water jet is moving in the material entry zone, i.e. the zone where the cutting wear is observed at lower values. At the same time, the increase in surface roughness with the increase in the feed rate and the cutting interval of the part at a high speed mean that the amount of abrasive that comes to the surface per unit time decreases. This effect, which increases the shrinkage and deformation wear in the cutting zone, results in an increase in the surface roughness value (Figure 6) and in the cutting profile taper [20]. In addition, as the feed rate increases, there is also an increase in the fluctuation value, which is one of the parameters determining the characteristic of the surface. The impact test, performed to see the effect of the feed rate on the surface roughness, showed that the feed rate effect is higher than the water pressure, abrasive size and type. Depending on the increase in the feed rate, the increase in surface roughness is an expected feature and the reduction in the speed of feed to improve surface roughness is the most common method recommended in the literature and by machine tool manufacturers [1]. As seen from Table 2, when the feed rate is increased from $10 \mathrm{~mm} / \mathrm{min}$ to $16 \mathrm{~mm} / \mathrm{min}$, the surface roughness increases and when the feed rate increases from $16 \mathrm{~mm} / \mathrm{min}$ to $45 \mathrm{~mm} / \mathrm{min}$, the surface roughness increases more than anticipated. It can be concluded that the amount of abrasive powder is much lower in the case of a shorter 
cutting interval at high speeds. In all processing operations, the $R z$ and $S m$ values increased in the deformation wear zone at the outlet of the water jet. The lowest $R z$ and $S m$ values were measured to be $9.83 \mu \mathrm{m}$ and $131.66 \mu \mathrm{m}$, respectively, in the region of shear wear on the first surface. The highest values were found to be $20.31 \mu \mathrm{m}$ and $271.33 \mu \mathrm{m}$, respectively, in the fifth processing operation carried out on the third surface. Also, surface 4 of part 5 did not break. This is because the cutting energy of the abrasive pressurized water at the unit time is not sufficient to cut the material. In addition, as the feed rate increases, there is also a decrease in the amount of abrasive per unit area, so, the fracture of the piece as a result of cutting did not occur.

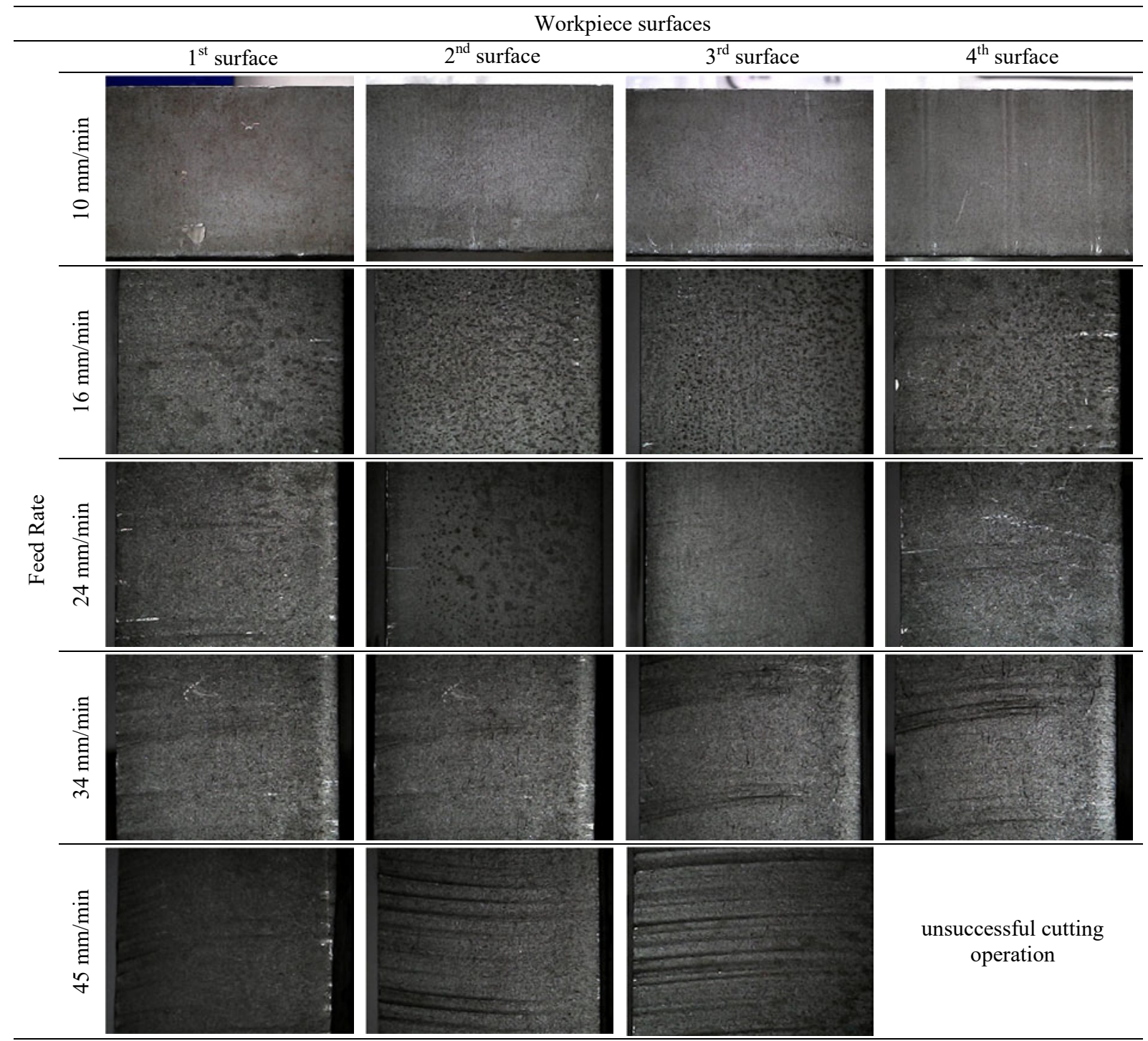

Fig. 6 Surface roughness and feed rate relation

The $\sqrt{\text { area }}$ values calculated using $R z$ and $S m$ values are the values of the average area of the maximum peak and valley values. These results are presented in Table 2 according to the surface roughness values and processing rates measured on the cut sections. In shear zones where the water jet enters the processing zone, these values are lower than in the deformation wear zones. At the same time, these values increased with an increase in the feed rate of the water jet. In short, the roughness of the wave structure and its dimensions changed with the rate of feed, and the surface roughness of each section increased towards the end of the cutting process. 
Theoretical fatigue life calculations consider the effect of fatigue life along cross sections of the surface roughness, as shown in Figures 7-11. All calculated " $\sigma_{w}$ " values are also shown in Table 2. The fatigue life between the inlet and the outlet of the water jet in all sections is reduced due to the increase in surface roughness. Since the surface is smoother at the points where the water jet starts to cut, the roughness of the peak-valley points has a lower effect on the fatigue initiator. For each cut made without interruption, the lowest fatigue life is calculated for the final surfaces. The lowest fatigue life is $265 \mathrm{MPa}$ on the third surface processed in the fifth operation, and the highest fatigue life is found to be $466.57 \mathrm{MPa}$ on the first surface processed at the feed rate of $V=10 \mathrm{~mm} / \mathrm{min}$.

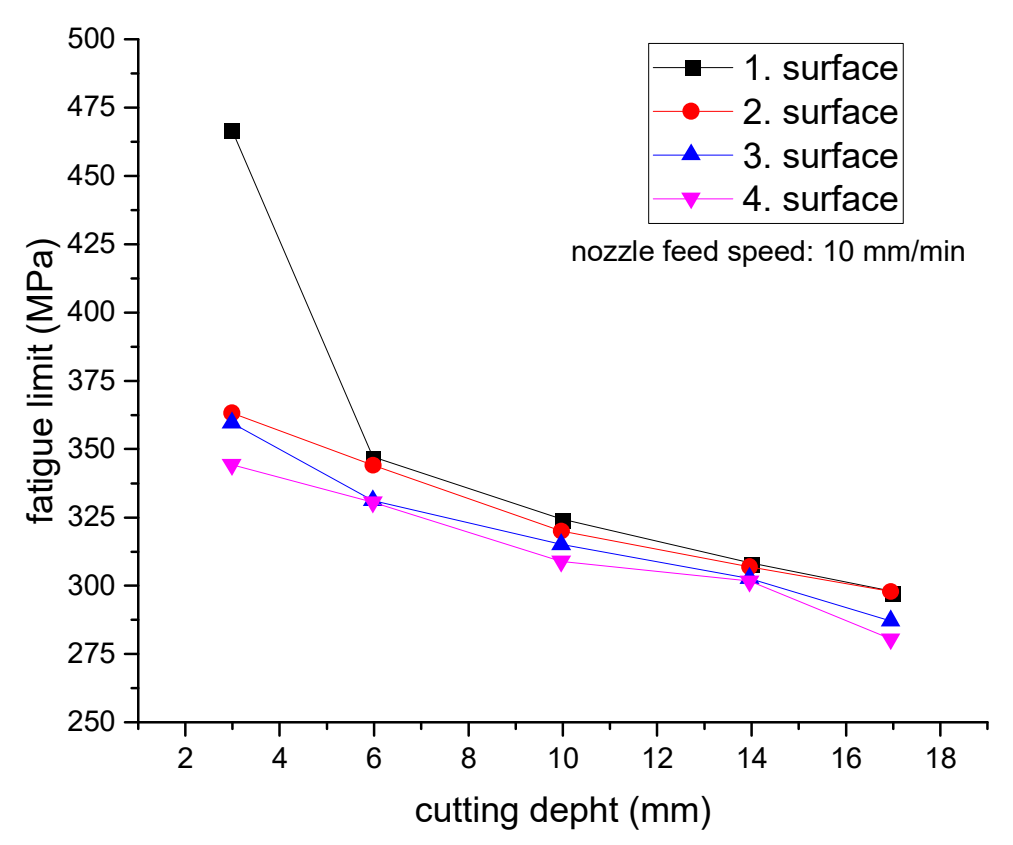

Fig. 7 Influence of cutting depth on fatigue life $(10 \mathrm{~mm} / \mathrm{min}$ feed rate)

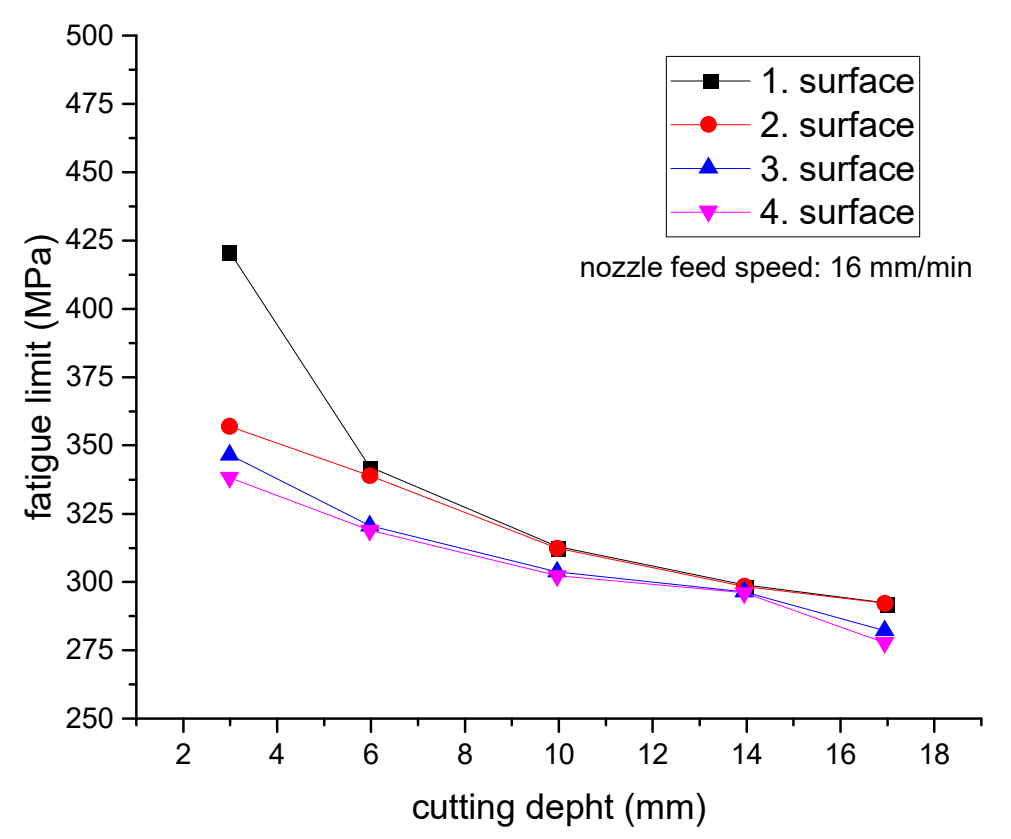

Fig. 8 Influence of cutting depth on fatigue life $(16 \mathrm{~mm} / \mathrm{min}$ feed rate) 


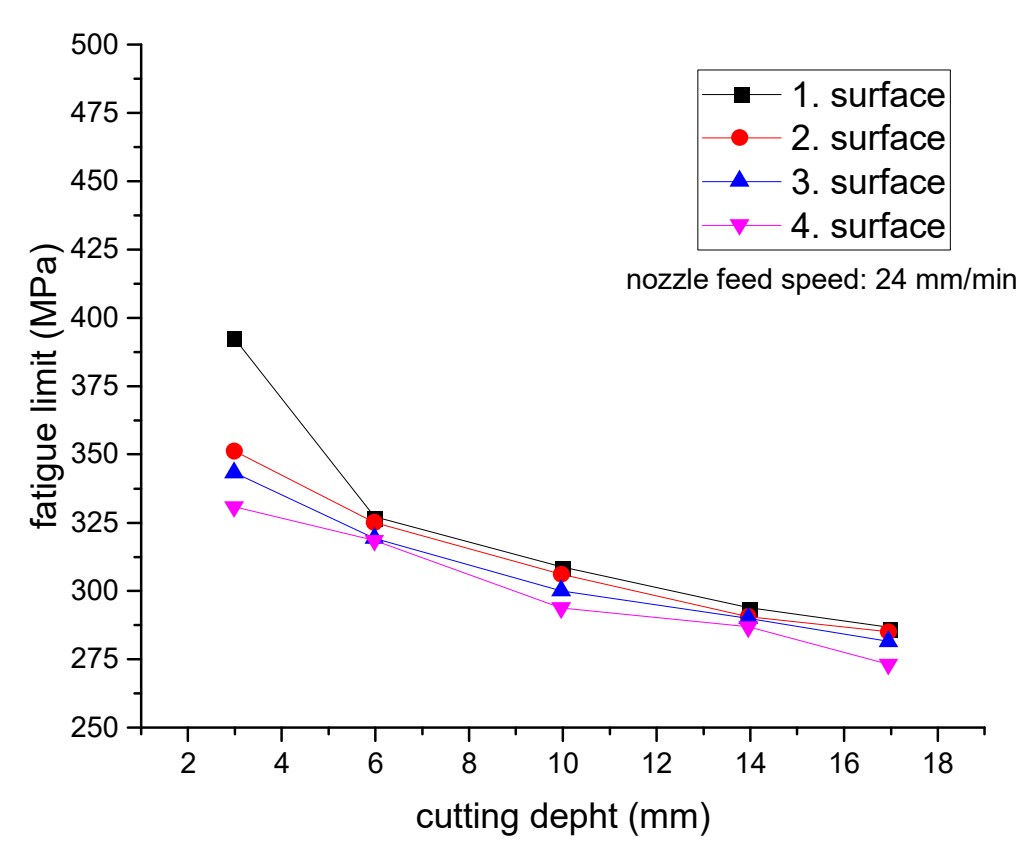

Fig. 9 Influence of cutting depth on fatigue life ( $24 \mathrm{~mm} / \mathrm{min}$ feed rate)

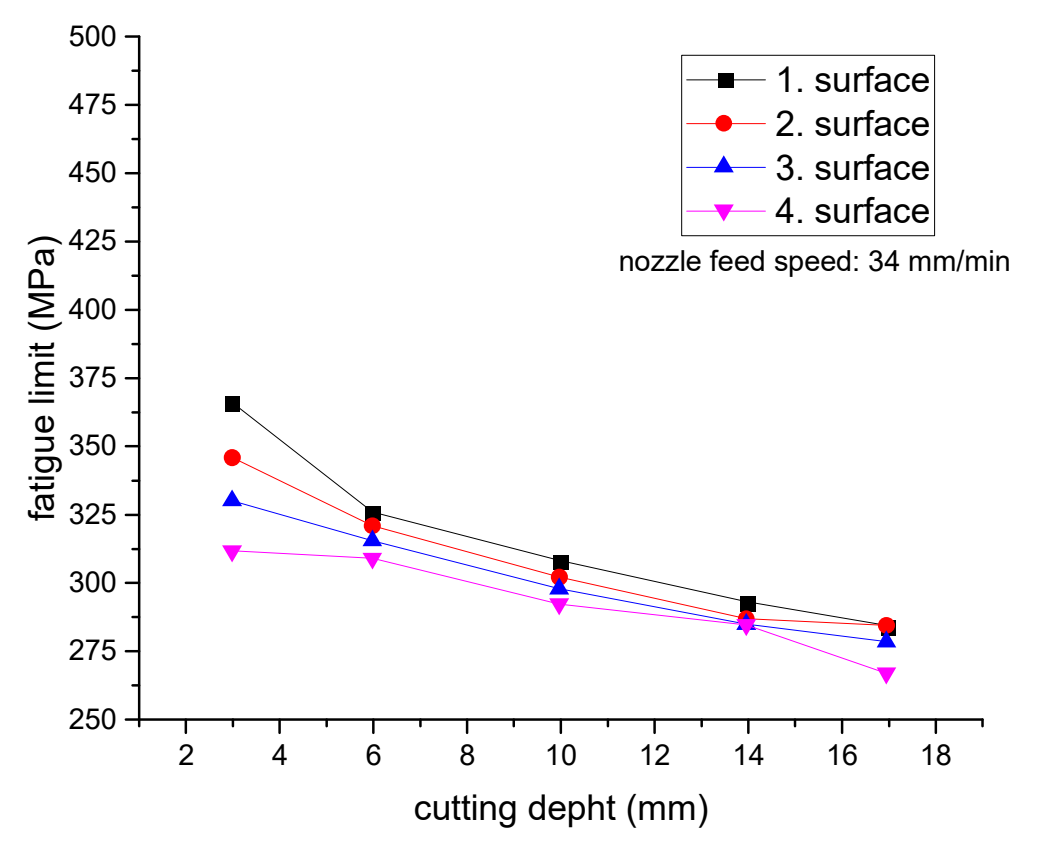

Fig. 10 Influence of cutting depth on fatigue life $(34 \mathrm{~mm} / \mathrm{min}$ feed rate) 


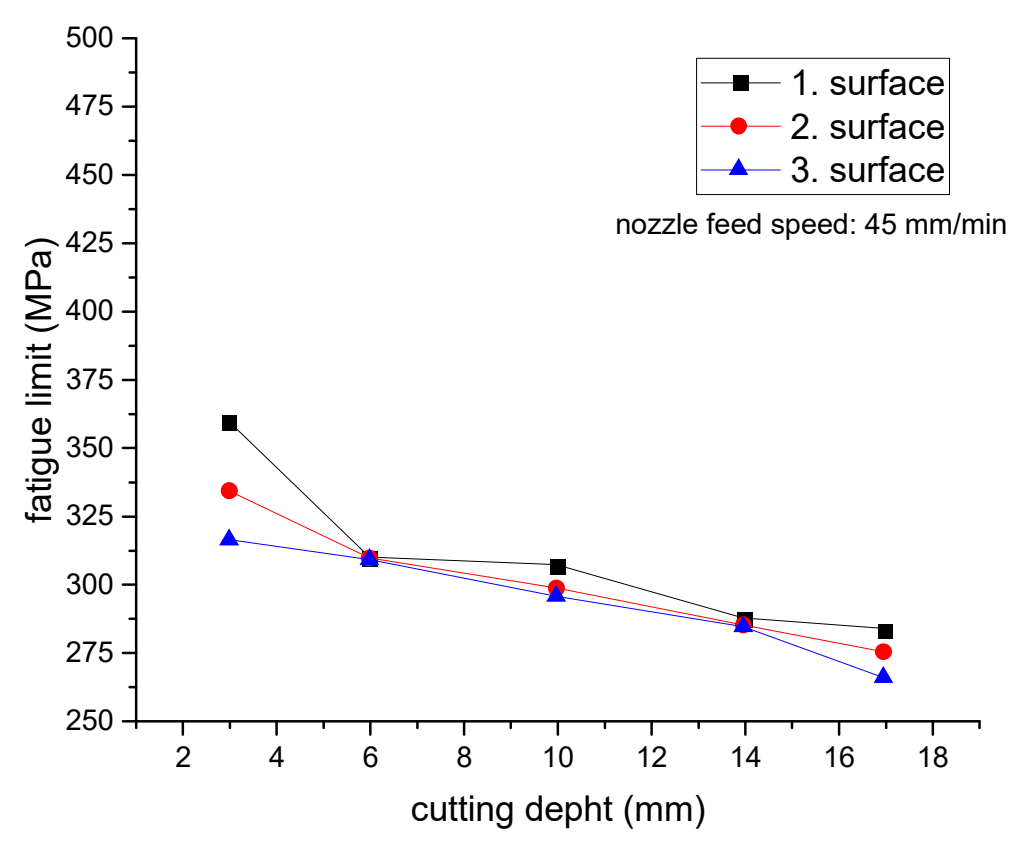

Fig. 11 Influence of cutting depth on fatigue life $(45 \mathrm{~mm} / \mathrm{min}$ feed rate)

Since the cutting process was not performed on four surfaces in the last processing operation in which the nozzle advancing speed was $45 \mathrm{~mm} / \mathrm{min}$, the fourth and the last surface were not separated from the main material. Since the feed rate was too high to perform the cutting operation, no measurement could be taken on this surface.

Depending on the feed rate, the change in the fatigue life limit value is shown in the graphs, Figure 12. Fatigue life is reduced because the surface deteriorates as the feed speed increases. The highest fatigue life was calculated at the feed rate of $10 \mathrm{~mm} / \mathrm{min}$ and the lowest fatigue life at $45 \mathrm{~mm} / \mathrm{min}$. During the process the amount of sand coming to the nozzle orifice must be constant and the sand must be homogeneous. Also, the mean particle size of the powder is taken into consideration in the performed processing operations. In this study, small particles in the powder mass were effective on the initial cutting surface, whereas large particles within the powder mass were effective on the subsequent surfaces. This is an inevitable situation due to the necessity of dust flow. That is to say, since the powder produced is not of the same size, fine-grained powder is peeled off from coarsegrained powder and it is a priority that fine-grained powder reaches the orifice at the beginning of the process. Thus, the surface roughness was the lowest on the surface cut first, and subsequently it increased on other surfaces. In the cutting processes performed with the same parameters, this situation was always observed and it was caused by the fact that dust masses are not homogeneous and this had a negative effect on the surface quality. As a result, in the finishing process, with the increase in the feed rate, the coarse grains present in the cutting zone in a very small amount prevented the cutting of the fourth surface in the fifth sample cutting. 

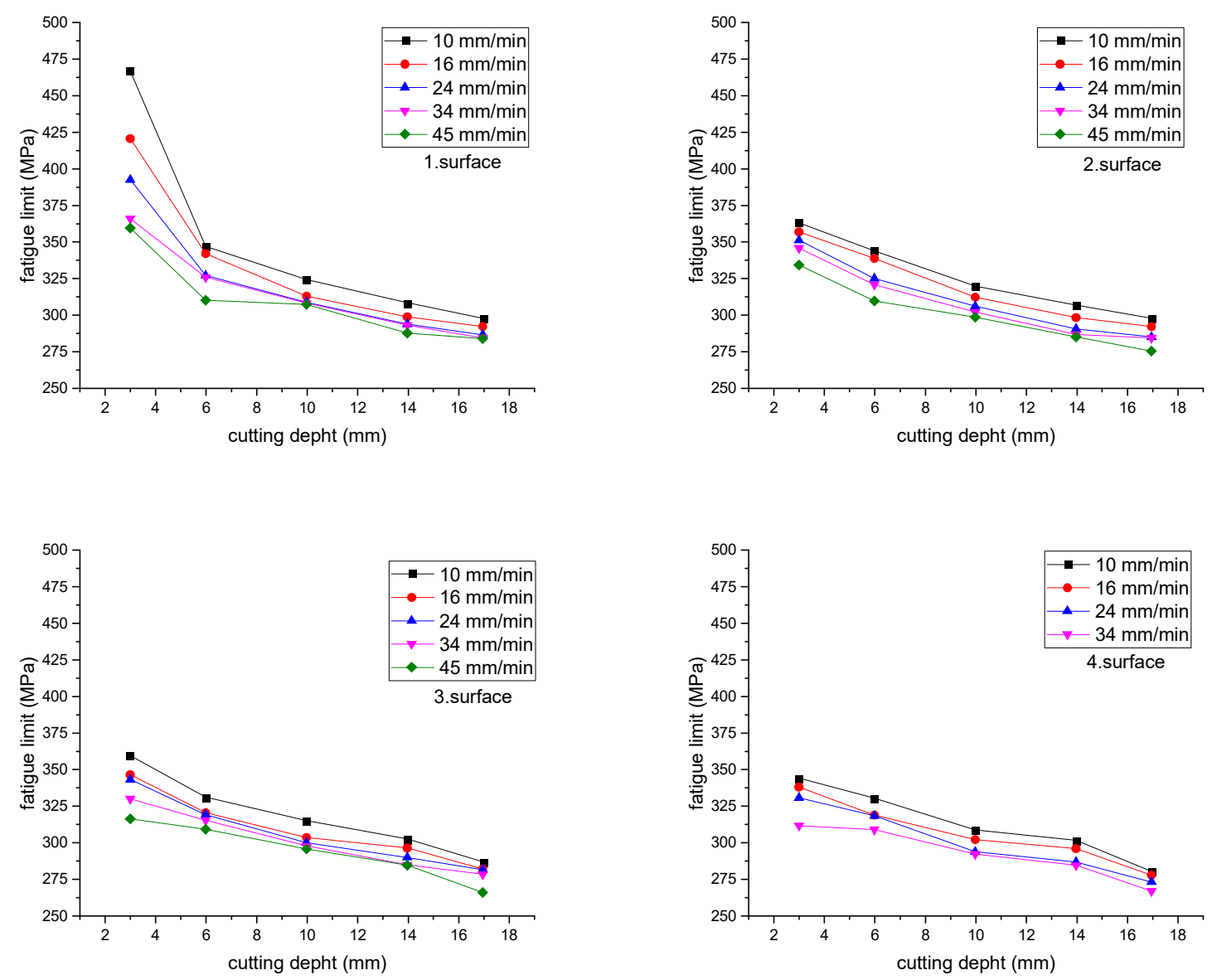

Fig. 12 Fatigue life changes on surfaces 1, 2, 3, and 4 depending on nozzle feed rate

\section{Results}

The following results have been obtained regarding surface roughness and theoretical fatigue life as a result of the measurements made on the specimens of AISI 1050 steel after they were processed by the AWJ with different range of cutting parameters.

- In terms of low surface roughness the optimum feed rate is $10 \mathrm{~mm} / \mathrm{min}$. Smooth surfaces were achieved in these processing conditions.

- Despite the fact that the powder reservoir was filled with new powder mass in each operation, the particle size during processing affected the surface quality from the beginning to the end of the process. From the beginning of the processing, fine-grained powder was effective and then the grain of the powder caused the surface to fluctuate with an increase in size. The surface roughness in the case when the processing was performed with the same value on this surface was higher than on the first surface. The worst surface quality appeared at the feed rate of $45 \mathrm{~mm} / \mathrm{min}$ on the surface that was cut last.

- In the last cutting operation carried out at the highest rate of feed, the fourth surface was not separated from the main material. Thus, the full cut did not occur. This is interpreted to be a result of the fact that coarse particles in the powder mass flew through the nozzle and that the feed rate was excessively high. The abrasive grain size and size distribution are important parameters affecting the performance of AWJ cutting.

- There is a directly proportional relationship between feed rate and surface roughness. The surface roughness increases also with the feed rate. Lower feed rates and lower surface 
roughness values were obtained both in the cutting wear zone and the deformation wear zone in the cutting performed with garnet powder. However, the change in surface quality is greater in the deformation wear zone. Low feed rates also lead to the formation of small taper angles.

- It was found that the deepest peak-valley values in the surface roughness profile increased as the nozzle feed rate increased. Therefore, $\sqrt{\text { area }}$ calculations were carried out using $R z$ and $S m$ roughness values, and the theoretical fatigue life of machined parts was calculated by using the $\sqrt{\text { area }}$ values. Accordingly, the increase in roughness caused by the increase in the feed rate adversely affects fatigue, and it has been determined that the lowest fatigue life has the highest roughness values. Thus, the highest theoretical fatigue stress values were obtained at the lowest feed rate and on the surfaces that were cut first. The highest fatigue life was calculated to be $466.57 \mathrm{MPa}$ on the first surface at the feed rate of $V=10 \mathrm{~mm} / \mathrm{min}$, and the lowest fatigue life was calculated to be $265.08 \mathrm{MPa}$ on surface 4 at the feed rate of $V=45 \mathrm{~mm} / \mathrm{min}$. This case is an indication that surface roughness on machine elements significantly reduces fatigue life by causing the notch effect.

\section{REFERENCES}

[1] Jain, V. K., “Advanced machining processes”, Allied Publishers, (2009).

[2] Cogun, C., "Computer-aided system for selection of nontraditional machining operations" Computers in industry, 169-179 (1993). https://doi.org/10.1016/0166-3615(93)90063-7

[3] Paul, S., Hoogstrate, A. M., Luttervelt Van, C. A. and Kals, H. J. J., “An experimental investigation of rectangular pocket milling with abrasive water jet", Journal of Materials Processing Technology, 73 (1-3): 179-188 (1998).

[4] Nanduri, M., Taggart, D. G., Kim, T. J., "The effects of system and geometric parameters on abrasive water jet nozzle wear”, International Journal of Machine Tools and Manufacture, 615-623 (2002). https://doi.org/10.1016/s0890-6955(01)00147-x

[5] Aich, U., Banerjee, S. and Bandyopadhyay, A., "Probal Kumar Das, Abrasive Water Jet Cutting of Borosilicate Glass", Procedia Materials Science, 775-785 (2014). https://doi.org/10.1016/j.mspro.2014.07.094

[6] Dittrich, M., Dix, M., Kuhl, M., Palumbo, B., Tagliaferri, F., "Process Analysis of Water Abrasive Fine Jet Structuring of Ceramic Surfaces via Design of Experiment”, Procedia CIRP, $442-447$ (2014). https://doi.org/10.1016/j.procir.2014.03.030

[7] A.W. Momber, R. Kovacevic, Principles of abrasive water jet machining, Springer Science\& Business Media 2012.

[8] Kovacevic, R., "Surface texture in abrasive waterjet cutting”, Journal of Manufacturing systems, 32-40 (1991). https://doi.org/10.1016/0278-6125(91)90045-4

[9] Klich, J., Klichová, D. \& Hlaváček, P. Effects of pulsating water jet on aluminium alloy with variously modified surface. Tehnički vjesnik, 24 (2) (2017), 341-345. https://doi.org/10.17559/TV-20140219100749

[10] Hloch, S., Srivastava, M., Krolczyk, J.B., Chattopadhyaya, S., Lehocká, D., Simkulet, V. \& Krolczyk, G.M. Strengthening Effect after Disintegration of Stainless Steel Using Pulsating Water Jet. Tehnički vjesnik, 25 (4) (2018), 1075-1079. https://doi.org/10.17559/TV-20170327134630

[11] T. Stenberg, E. Lindgren, Z. Barsoum, I. Barmicho, Fatigue assessment of cut edges in high strength steel-Influence of surface quality, Materialwissenschaft und Werkstofftechnik 48(6) (2017) 556-569. https://doi.org/10.1002/mawe.201600707

[12] Ohman, J.L., "Abrasives: Their characteristics and effect on waterjet cutting”, Proceedings of the 7th American Waterjet Conference, 351-362, USA (1993).

[13] Azmir, M.A., Ahsan, A.K., "A study of abrasive water jet machining process on glass/epoxy composite laminate", Journal of Materials Processing Technology, 209: 6168-6173 (2009).

https://doi.org/10.1016/j.jmatprotec.2009.08.011 
[14] D. Begic-Hajdarevic, A. Cekic, M. Mehmedovic, A. Djelmic, Experimental study on surface roughness in abrasive water jet cutting, Procedia Engineering 100 (2015) 394-399. https://doi.org/10.1016/j.proeng.2015.01.383

[15] Akkurt, M., “AlS1 1030 çeliginin asındırıcılı su jeti ile kesilmesinde yüzey pürüzlülüğünün ve kesme önü geometrisinin incelenmesi',,Cilt:15, 1-11 (2009).

[16] Limbachiya, V.J., Patel, D.M., "Parametric analysis of abrasive water jet machine of aluminium material",Vol. 1, Issue 2, pp.282-286 (2011).

[17] Chao, J., Geskin, E., Chung, Y., "Investigations of The Dynamics of The Surface Topography Formation During Abrasive Waterjet Machining", Proc. of 11th Int. Conf. On Jet Cutting Technology, Scotland, (1992). https://doi.org/10.1007/978-94-011-2678-6_39

[18] Reddy, D. S., Kumar, A. S. and Rao, M. S., "Parametric Optimization of Abrasive Water Jet Machining of Inconel 800H Using Taguchi Methodology", Universal Journal of Mechanical Engineering, 158-162 (2014). https://doi.org/10.13189/ujme.2014.020502

[19] Murakami, Y.: Metal Fatigue: Effects of Small Defects and Nonmetallic Inclusions. Elsevier Science, Oxford (2002)

[20] Wang, J., Wong, W.C.K., "A Study of Abrasive Waterjet Cutting of Metallic Coated Sheet Steels", International Journal of Machine Tools \& Manufacture, 39: 855-870 (1999). https://doi.org/10.1016/s0890-6955(98)00078-9

$\begin{array}{lll}\text { Submitted: } & 26.6 .2018 & \begin{array}{l}\text { Dr. İsmail Tekaüt } \\ \text { Gazi University } \\ \text { Vocational School of Technical Sciences, } \\ \text { Department of Machine, Ankara Turkey }\end{array} \\ \text { Accepted: } & 30.11 .2018 & \text { Depros }\end{array}$

